\title{
Early Detection of Room Fires Through Acoustic Emission
}

\author{
WILLIAM L. GROSSHANDLER and EMIL BRAUN \\ Building and Fire Research Laboratory \\ National Institute of Standards and Technology \\ Gaithersburg, MD 20899, USA
}

\begin{abstract}
Acoustic emission (AE) has been shown to be a viable concept for the early indication of an open flame impinging on various structural materials. To assess its effectiveness in a more realistic environment, experiments have been performed in a $2.4 \mathrm{~m}$ cubical room constructed of gypsum board and wood. AE transducers were mounted on top of a ceiling joist and on a wall stud. The threats examined were a natural gas fire producing a thermal load up to $125 \mathrm{~kW}$, and a charring condition achieved by attaching a $550 \mathrm{~W}$ electrical heater to a wall stud. A signal discernable above the background was recorded from at least one AE sensor in six of nine situations. In each case, measurable acoustic emission occurred before a noticeable increase in voltage from the thermocouple mounted adjacent to the AE sensor. The conclusion is that $\mathrm{AE}$ emission appears to be sufficiently sensitive to detect two particular threats, and that an overheated condition in a wall or ceiling can be detected if it is not more than $3 \mathrm{~m}$ from the transducer. Additional experiments are required to identify signals that are likely to complicate the differentiation between a false and a true fire event.
\end{abstract}

KEY WORDS: fire detection, acoustic properties, acoustic sensors

\section{INTRODUCTION}

The heat produced by a small fire or by an electrical circuit overload will cause the materials surrounding the heat source to expand. If the affected components heat unevenly or are of dissimilar material so that expansion is not uniform, the stressed material may emit acoustic waves at frequencies up to $500 \mathrm{kHz}$ when the stress is suddenly relieved. The boiling of trapped moisture or bursting of gas bubbles within a plastic also releases acoustic energy. There is a characteristic signature associated with these processes which can be used to detect a serious overheating event, possibly prior to ignition.

In a recent study [1] the viability of using the acoustic signal emitted by a variety of structural materials exposed to nonuniform heating as an early indicator of a fire was assessed. The acoustic emission (AE) process, its application to fire detection, and the results of a series of tests were presented. The general behavior of the materials studied could be explained qualitatively by comparison to the simplified theory developed by Clough [2] which predicts acoustic emission during laser heating of a surface. A further description 
of the acoustic emission process can be found in reference [1] and in the review article by Wadley [3].

In order to assess the potential for $\mathrm{AE}$ to detect the early stages of a fire, several full-scale room tests were conducted with two types of fire threats: (1) an electrical ignition within the wall cavity, and (2) a small flaming fire in the compartment. These experiments were to determine if the rate of $\mathrm{AE}$ events under closer-to-real construction conditions was comparable to the rate measured previously in the small-scale laboratory experiments [1]. Since in the present study background noise was kept to a minimum, the impact of extraneous noise on the ability of AE detectors to discriminate between a fire and non-fire condition was not determined.

\section{EXPERIMENTAL FACILITY}

The experimental structure was nominally cubical, $2.4 \mathrm{~m}$ on a side, with a standard size door opening centered on one wall. The walls and ceiling were covered with commercially available $12 \mathrm{~mm}$ gypsum sheets nailed to a wooden superstructure. The studs had a $38 \mathrm{~mm}$ by $89 \mathrm{~mm}$ cross-section and were placed on $600 \mathrm{~mm}$ centers. The wooden ceiling joists, 38 $\mathrm{mm}$ by $176 \mathrm{~mm}$, were attached with long screws to the studs, as shown in FIGURE 1. The center portion of the ceiling was dropped by an amount equal to the height of the beams for ease of construction and instrumentation.

Three Physical Acoustic Corporation" piezoelectric transducers were mounted on the central wall stud and ceiling beam, located as shown in FIGURE 1. The transducers were coupled to the wooden surface with just enough silicone vacuum grease to hold them in place during the experiments. The wall stud was notched to accommodate the transducer in a horizontal position. Signals from the transducers passed through PAC model 1220 A preamplifiers and a PAC model 3000 power supply, amplifier and signal processor as described in the earlier study [1].

Two different heat sources were used to simulate an overheated condition. The first was a $550 \mathrm{~W}$ electrical heater normally used for starting charcoal fires. It was mounted on the center wall stud, halfway between the floor and ceiling. Copper conduit clamps were used to ensure good contact with the wood. The second heat source was a $0.3 \mathrm{~m}$ diameter natural gas pool fire, located on the centerline of the room close to the back wall. Chromel-alumel thermocouples were used to monitor the temperature at the locations indicated in the figure. The voltages were compensated and stored at ten second intervals in a data acquisition computer. Of particular interest were the temperatures at the location of the AE sensors, the temperature at the electrical heater, and the ceiling temperature above the gas fire. An ACpowered ionization smoke detector was installed on the ceiling close to the door opening and the temperature adjacent to it was measured.

\footnotetext{
- Certain commercial products are identified in this report in order to adequately specify equipment used. Such identification does not imply recommendation by the National Institute of Standards and Technology, nor does it imply that this equipment is the best available for the purpose.
} 

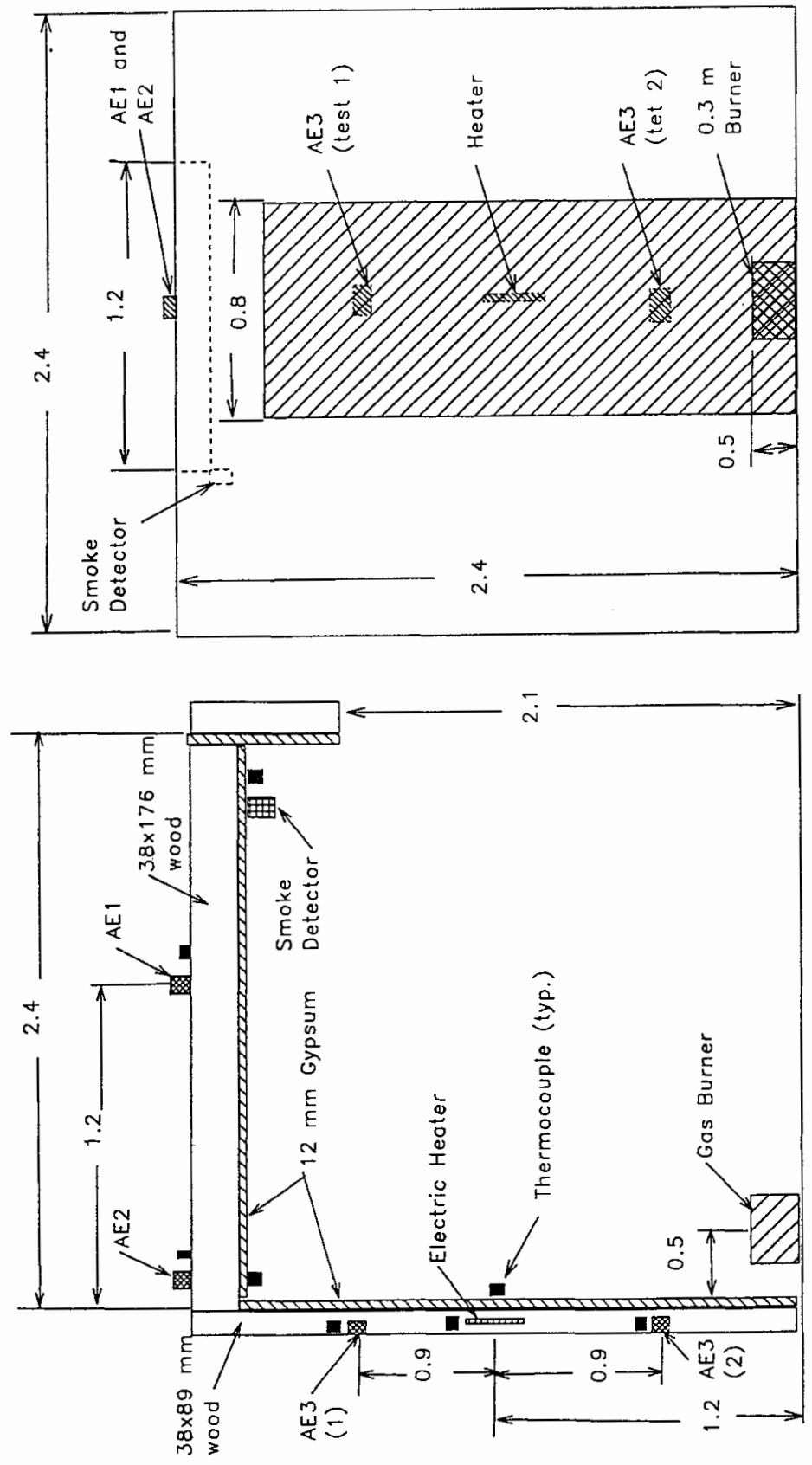

FIGURE 1. Facility for assessing performance of acoustic emission fire detector. 


\section{EXPERIMENTAL RESULTS}

The acoustic emission signal appears as a voltage burst at a frequency close to $150 \mathrm{kHz}$ for a duration of around a millisecond. It is characterized by a peak amplitude and total energy, and one burst can follow another a millisecond later. The number of $\mathrm{AE}$ events, $\mathrm{N}$, (i.e., the number of voltage bursts measured), the cumulative energy released, $E$, and the rate of emission all serve as a basis to detect the overheated condition.

\section{Electrical Heater Experiments}

Situations in which the products of pyrolysis and combustion are obstructed from entry into a room are difficult for many fire sensors to detect because traditional fire detection systems depend upon the convective transport of heat or mass from the fire to a remote sensor location. Two experiments were run to evaluate the AE sensors using an electrical heater to simulate an overheated condition in the wall cavity. In the first test, AE sensor $\# 3$ was located a little less than a meter above the heater. The background temperature and $\mathrm{AE}$ levels were monitored for 5.7 minutes, at which time full power was applied to the $550 \mathrm{~W}$ electrical heater. The temperature of the wood close to the electrical heater increased rapidly once the electricity was applied, reaching a maximum of $180^{\circ} \mathrm{C}$ above the ambient at the end of the heating period. The temperature inside the room on the other side of the wall from the heater rose $22{ }^{\circ} \mathrm{C}$ above the environment, while the temperature at the location of the smoke detector did not increase by a discernible amount. Because AE3 was located above the heating element, natural convection caused a significant temperature increase in its environment. The test was terminated when the operational temperature exceeded $50{ }^{\circ} \mathrm{C}$ in order to avoid damage to the transducer.

One emission event was recorded by AE3 during the 5.7 minute background check; none was recorded by $\mathrm{AE} 1$ or AE2. AE2 did not respond at all during the heating period either, while AE1 produced two emissions. A large amount of activity was recorded by AE3. After a 1.3 minute delay, the number of emissions suddenly jumped, with emissions continuing at a steady pace until 9.6 minutes, when the transducer was removed to prevent it from overheating. The cumulative energy increased in a parallel manner. The total number of emissions was 305 , yielding an average rate over the heating period of $78 / \mathrm{min}$. The smoke detector did not respond at all in this first test, nor did the two AE transducers mounted in the ceiling indicate an overheated situation. While AE3 did produce a strong signal within 1.5 minutes of the power being applied, the thermocouple provided an equally early indication of the heating.

The wall panels and studs were replaced and a second test was run in which transducer AE3 was located below the heating element, where the temperature increase was limited to conduction through the wood. This arrangement allowed the experiment to be run for a longer period of time before a secondary effect of temperature on the transducer itself became significant. Temperature profiles taken during the second test are shown in FIGURE 2. After a background check period of 6.5 minutes, power to the heater was started and the temperatures increased as shown in FIGURE 2. The temperature measured adjacent to the heater, $T_{h}$, rose in an orderly manner and appeared to level off at 30 minutes, when a 300 ${ }^{\circ} \mathrm{C}$ jump was observed, followed by a steep decline to the 46 minute point, when the power was turned off. Inspection of the heater, wall stud, and gypsum board after the system had 


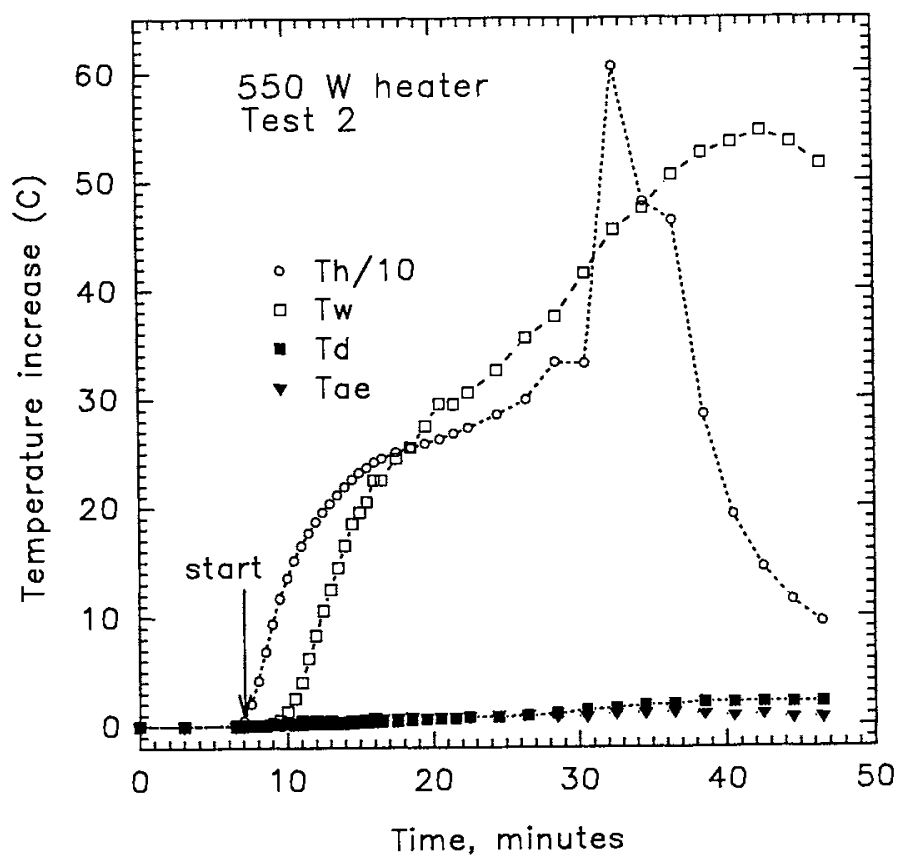

FIGURE 2. Temperatures in electrical heater experiment. Location of thermocouples: ae, next to AE3; h, wood stud near heater; $w$, inside wall adjacent to heater; $d$, smoke detector.

cooled indicated that a char layer had formed about $10 \mathrm{~mm}$ deep under the heater. A number of crevices had formed in the wood and the surface was disrupted, leading to the conjecture that the thermocouple had become dislodged from the surface, recontacted the surface as it expanded, and then lost contact as buckling of the surface occurred. The temperature in the room directly on the other side of the wall from the heating element, $T_{w}$, increased by 55 ${ }^{\circ} \mathrm{C}$. The temperature at transducer AE3, $\mathrm{T}_{\text {ace }}$, increased less than two degrees during the entire test, and the temperature increase near the smoke detector, $T_{d}$, was about four degrees.

The amplification of AE transducers 1 and 2 was increased $3 \mathrm{~dB}$ to $89 \mathrm{~dB}$ in this second test. The increased amplification caused the background emission from AE2 to rise to a level of $4 / \mathrm{min}$. Amid this high background only one emission had enough energy to be recognizable as occurring during the heating period. There was no background emission measured by $\mathrm{AE} 1$, located on top of the center joist, in spite of the increase in amplification. During the forty minute heating period there were 16 emissions, yielding an average rate of $0.43 / \mathrm{min}$, with the first emission occurring about two minutes after the heater was started. FIGURE 3 is a plot of the number of emissions and cumulative energy from AE1. The instantaneous rate of emission approached $1 / \mathrm{min}$ about five minutes into the heating period, which is well above the background signal measured with this particular transducer. The amplification was maintained at $86 \mathrm{~dB}$ for $\mathrm{AE} 3$. Within a minute and a half, the transducer began detecting emissions at a rate in excess of $50 / \mathrm{min}$, following the initial period without heat during 


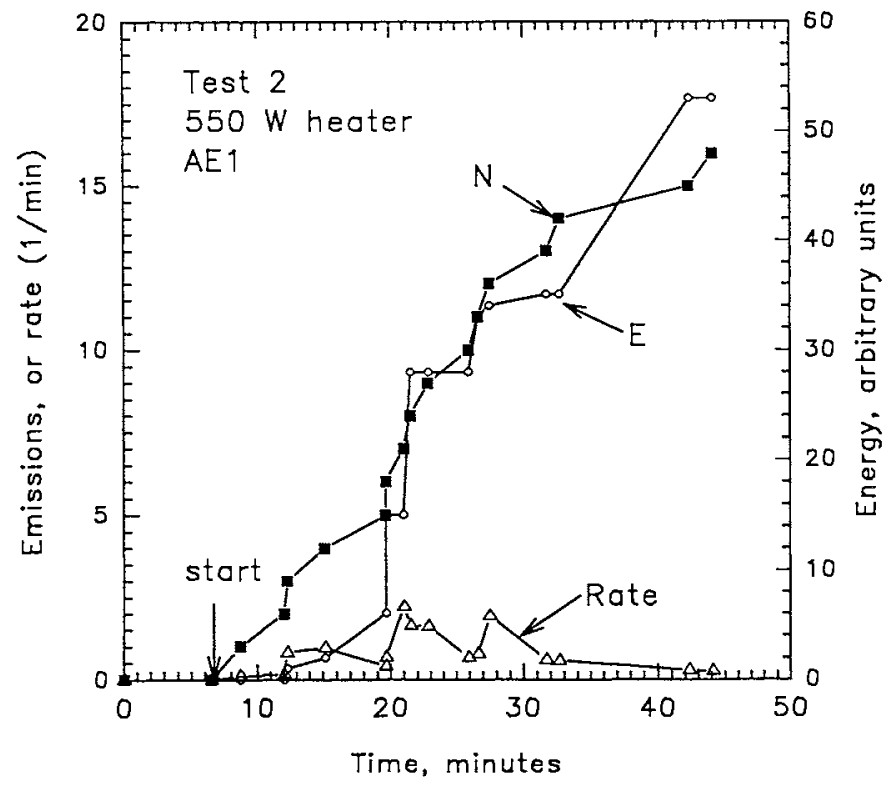

FIGURE 3. Cumulative energy released, $E$, number of $A E$ events, $N$, and instantaneous rate of emission from AE1 in second electrical heater experiment. Amplification is $+89 \mathrm{~dB}$.

which no emissions were measured. FIGURE 4 shows the history of cumulative energy and emission number, with an accelerating number of events occurring about 30 minutes into the test. The instantaneous rate of emission exceeded $300 / \mathrm{min}$ (the maximum imposed by the data analysis method) many times during the latter period of heating.

Wisps of smoke were first observed above the room about six minutes into test two. Very little smoke was noticed within the room, but an odor was unmistakably present. The smoke detector located in the test room did not respond at any time during the experiment.

\section{Gas Burner Experiments}

The gypsum boards and wall studs were replaced, and AE3 was relocated as in test number 1 , about $0.9 \mathrm{~m}$ above the mid-height of the room. After an initial five minutes of background data, the gas flow to the bumer was set to deliver $12 \mathrm{~kW}$ of heat to the room for a ten minute period. At that time, the fire was increased to $25 \mathrm{~kW}$, followed by a $25 \mathrm{~kW}$ increase each five minute interval later, reaching a maximum heat input of $125 \mathrm{~kW}$ at 35 minutes into the test. FIGURE 5 is a plot of the temperature increase in the room. The maximum temperature was located on the ceiling above the bumer. The largest increase was $210^{\circ} \mathrm{C}$, measured just before the burner was extinguished. The temperature increase 


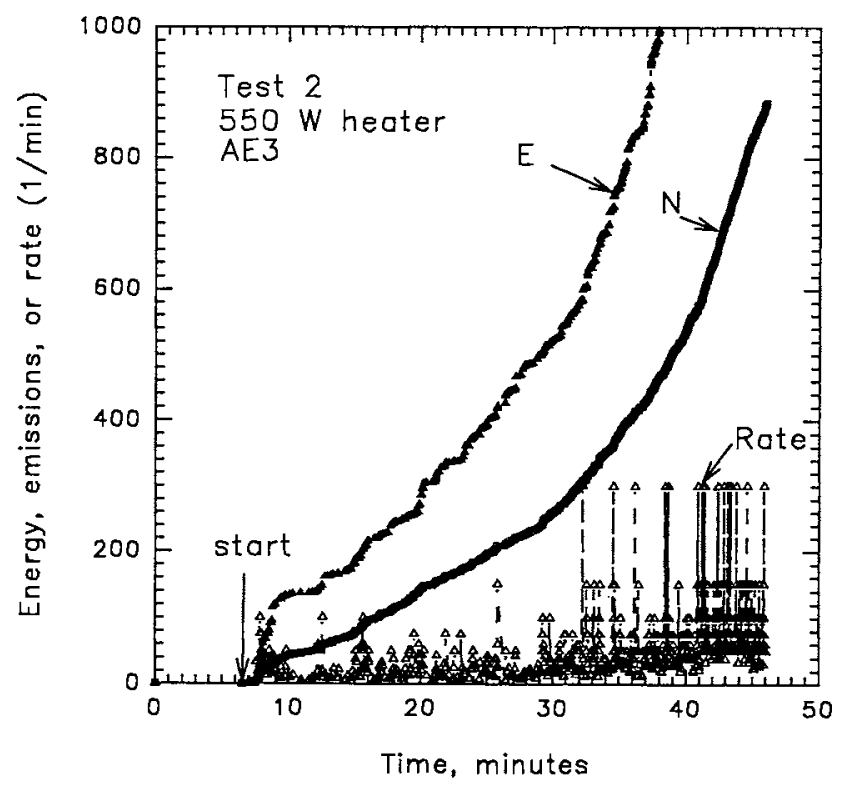

FIGURE 4. Cumulative energy released, $E$, number of $A E$ events, $N$, and instantaneous rate of emission from AE3 (below heater) in second experiment. Amplification is $+86 \mathrm{~dB}$.

measured at the smoke detector was similar in magnitude, and both temperatures responded within seconds to the changes in gas flow. The increasing size of the fire is indicated by the vertical arrows in the figure. The temperature increase above the ceiling joist, where AE1 and AE2 were located, was indiscernible until the fire reached its maximum value near the end of the experiment. The transducer mounted in the wall, AE3, increased two degrees in the first five minutes of the fire, and $10^{\circ} \mathrm{C}$ after 15 minutes of burning. The temperature at $\mathrm{AE} 3$ exceeded $50^{\circ} \mathrm{C}$ about 30 minutes into the experiment.

The amplification on AE2 was reduced to $86 \mathrm{~dB}$ to eliminate the large background signal observed in the previous test. AE1 and AE3 were set to an amplification factor of $+89 \mathrm{~dB}$. During the five minute background check, one emission was recorded by AE1 and two each by AE2 and AE3. For the transducer located above the ceiling joist in the center of the room, $\mathrm{AE} 1$, the emission rate exceeded the background twenty minutes after ignition. The number of events and cumulative energy recorded by AE1 are shown in FIGURE 6. AE3 began to detect the fire seven minutes after the bumer was lit. From FIGURE 7, the steady increase in the number of AE events can be observed even when the fire is $25 \mathrm{~kW}$ and smaller. The greatest activity was recorded from the transducer AE2, located above the comer of the room closest to the centerline of the burner. This is shown in FIGURE 8. A maximum emission rate of $16 / \mathrm{min}$ was found ten minutes into the bum. The average rate of emission over the 31 minutes that the bumer was lit was $1.2 / \mathrm{min}$. 


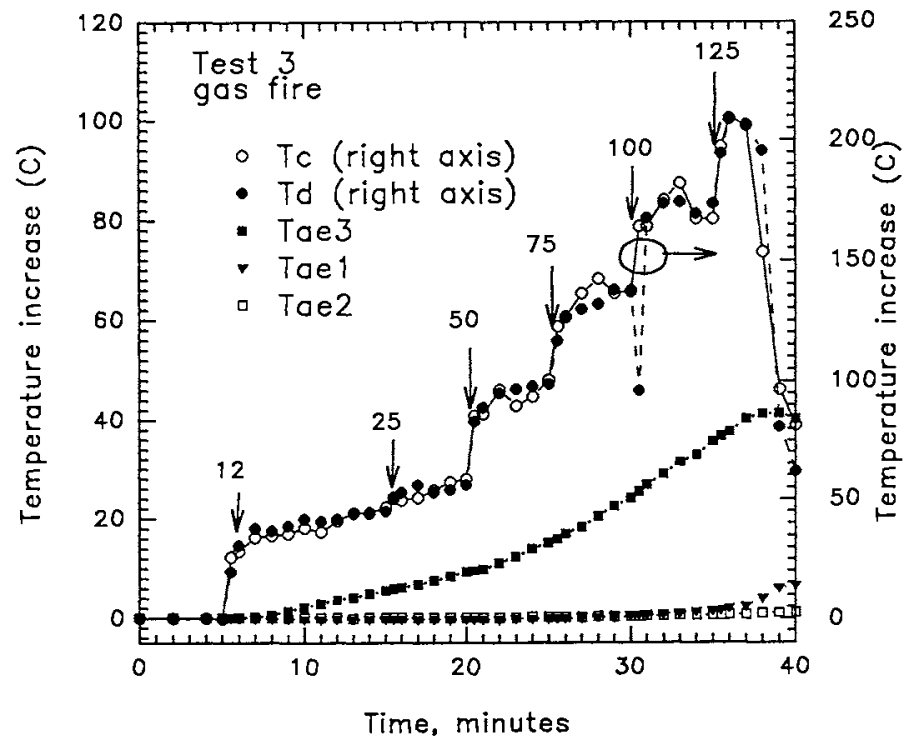

FIGURE 5. Temperature in natural gas burner experiment. Thermocouple location: ae1, ae 2 and ae 3 are adjacent to respective $\mathrm{AE}$ transducers; c, ceiling above burner; $d$, smoke detector. Vertical arrows designate increase in flame size.

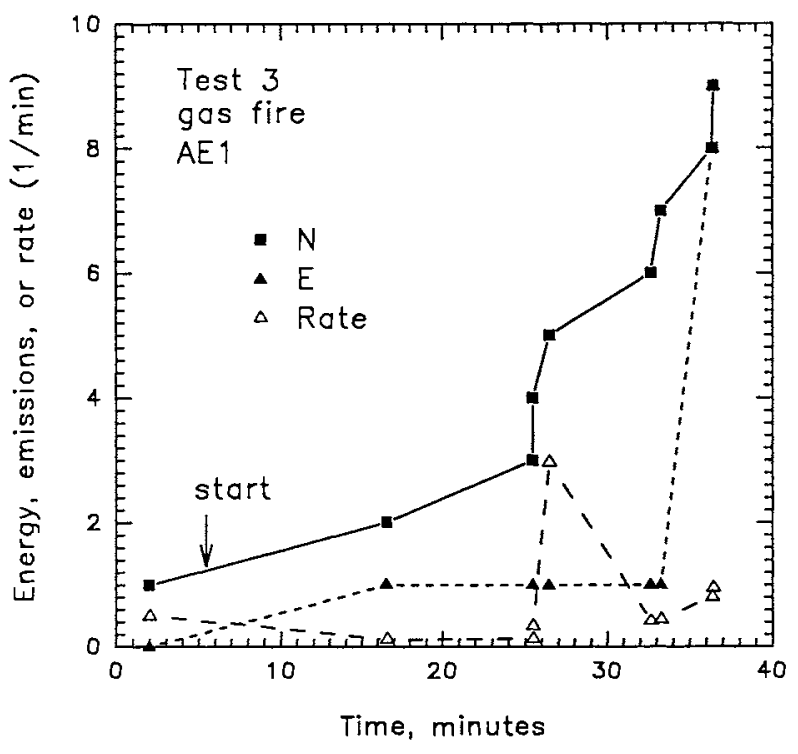

FIGURE 6. Cumulative energy released, E, number of AE events, $N$, and instantaneous rate of emission from AE1 in gas bumer experiment. Amplification is $+89 \mathrm{~dB}$. 


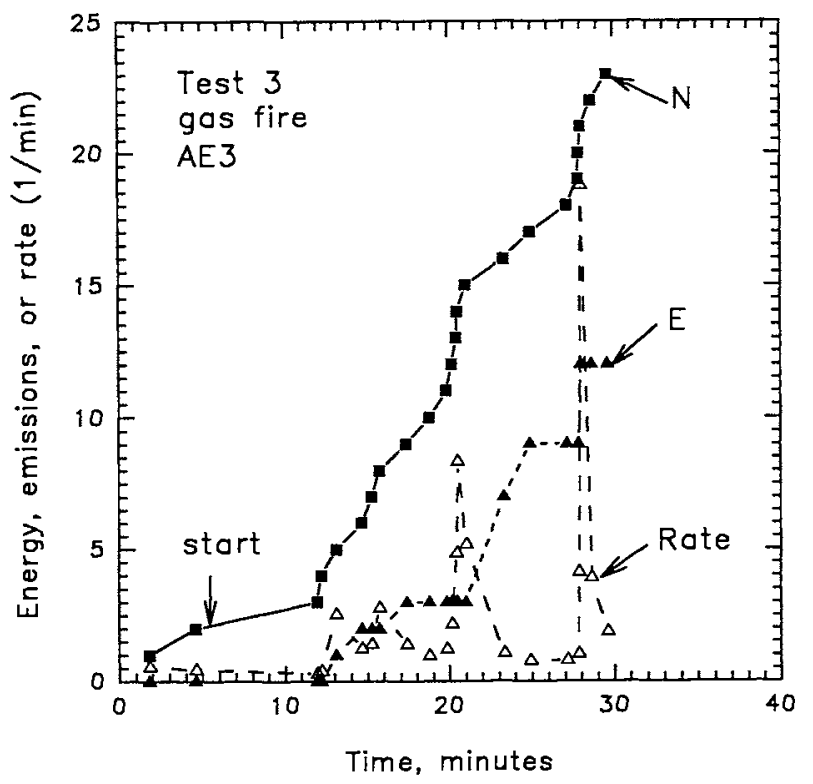

FIGURE 7. Cumulative energy released, $E$, number of AE events, $N$, and instantaneous rate of emission from AE3 in gas burner experiment. Amplification is $+89 \mathrm{~dB}$.

The smoke level was very light with the natural gas burner. The flames reached the ceiling about $50 \%$ of the time when the gas flow was set to $100 \mathrm{~kW}$. After the test was completed, inspection revealed that the ceiling was lightly scorched in a $0.3 \mathrm{~m}$ circle directly above the burner, but that the paper layer on the gypsum board had not been ignited. The ionization smoke detector did not detect the presence of smoke anytime during the 38 minute test.

\section{DISCUSSION}

The average energy, amplitude and duration of each acoustic emission were measured during the experiments. This information is useful in helping to discriminate a response to a fire from the background emission. TABLE 1 is a summary of the average data for the electrical heater and gas burner experiments. The background signal can be seen to be zero in four of the six experiments with the electrical heater. The acoustic emission rate from AE3 in Test 1 is more that two orders of magnitude higher than the background. The duration and energy of an average response are about twice the background level. On the other hand, AE2 was unable to detect the hazard in either test. The amplification was too low to produce a response in Test 1 . In Test 2 the noise was amplified as much as any signal. The average duration, energy and amplitude measured by AE2 provided no indication of a fire threat. 


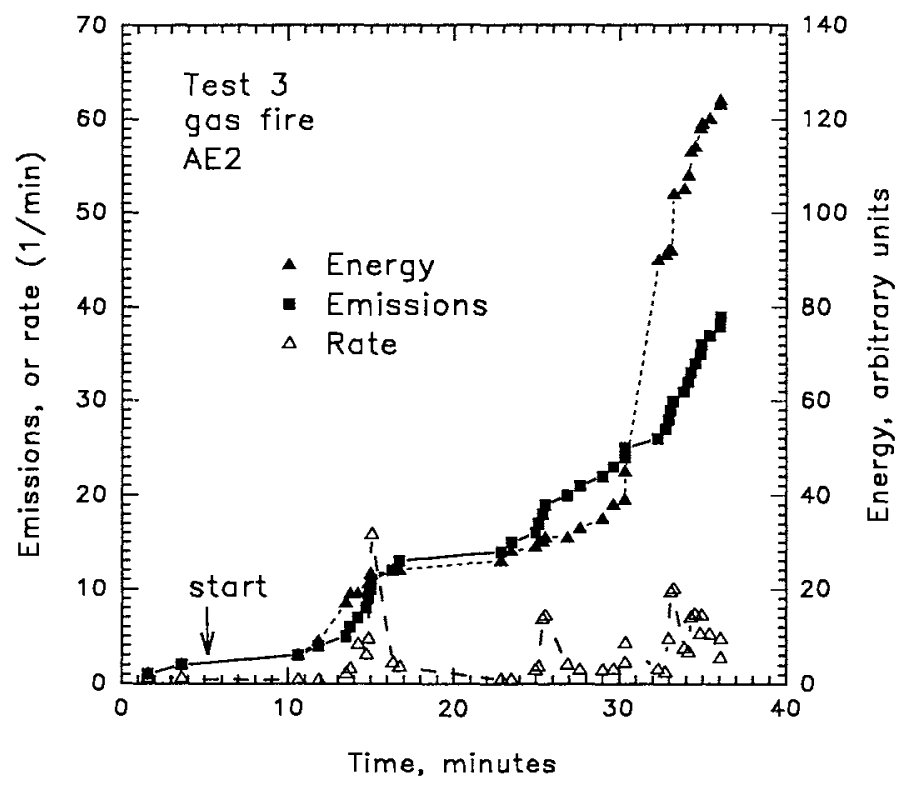

FIGURE 8. Cumulative energy released, $E$, number of $A E$ events, $N$, and instantaneous rate of emission from $\mathrm{AEl}$ in gas bumer experiment. Amplification is $+86 \mathrm{~dB}$.

The emission rates from AE2 and AE3 in response to the gas burner fire are two to three times greater than the background levels. (See Test 3, TABLE 1.) The average duration, energy and amplitude are all larger than the background, as well, although in the case of AE2 the differences between the background and the response for the average duration and amplitude are not statistically meaningful. The emission rate from AE1 is only slightly higher than the background, and the amplitude is less. The non-zero average energy level for this transducer provides a bit of reinforcement that the $A E$ events are in response to an overheated condition.

The response time of the $\mathrm{AE}$ detector can be characterized in a number of ways. For the purpose of discussion, let the response time be defined as the delay between the onset of heating and a measured signal (i.e., emission rate) equal to at least twice the background level. The response of the AE detector can be compared to the time it takes for the thermocouple adjacent to it to increase $6^{\circ} \mathrm{C}$ above the ambient condition. TABLE 2 lists these two characteristic times determined from the three tests which were conducted. AE3 detected all three hazards, responding between 1.3 and 7 minutes after the heating period began. The other AE transducers failed to respond at least once within the allotted test time. The thermocouple located at each AE device in all cases took longer to exceed the threshold temperature than the corresponding AE transducer. While the thermocouple located directly above the gas burner responded to the temperature increase within seconds of when the fire 
TABLE 1. Response of AE transducers to $550 \mathrm{~W}$ electrical heater (Tests 1 and 2) and natural gas pool fire (Test 3 ).

\begin{tabular}{l|c|c|c|c|c|c}
\hline \multirow{2}{*}{} & \multicolumn{2}{|c|}{ AE \#1 } & \multicolumn{2}{c|}{ AE \#2 } & \multicolumn{2}{c}{ AE \#3 } \\
\cline { 2 - 7 } & $\begin{array}{c}\text { Back- } \\
\text { ground }\end{array}$ & Response & $\begin{array}{c}\text { Back- } \\
\text { ground }\end{array}$ & Response & $\begin{array}{c}\text { Back- } \\
\text { ground }\end{array}$ & Response \\
Rate, min-1 & & & & & & \\
Duration, ms & 0 & 0.34 & 0 & 0 & 0.18 & 78.0 \\
Energy, a.u. & 0 & 228 & 0 & 0 & 54 & 89 \\
Amp., a.u. & 0 & 5.5 & 0 & 0 & 3.0 & 6.4 \\
\hline \multicolumn{1}{c|}{ Test 2: } & & & 0 & 0 & 51 & 47 \\
Rate, min-1 & 0 & 0.43 & 4.15 & 4.37 & 0 & 22.4 \\
Duration, ms & 0 & 61 & 54 & 32 & 0 & 97 \\
Energy, a.u. & 0 & 3.3 & 1.4 & 1.0 & 0 & 4.9 \\
Amp., a.u. & 0 & 41 & 36 & 37 & 0 & 46 \\
\hline \multicolumn{1}{c|}{ Test 3: } & & & & & & \\
Rate, min-1 & 0.20 & 0.25 & 0.40 & 1.19 & 0.40 & 0.85 \\
Duration, ms & 15 & 20 & 67 & 68 & 0 & 20 \\
Energy, a.u. & 0 & 1.1 & 2.0 & 3.2 & 0 & 0.6 \\
Amp., a.u. & 40 & 36 & 42 & 43 & 41 & 57 \\
\hline
\end{tabular}

TABLE 2. Characteristic response times comparing acoustic emission to a $6{ }^{\circ} \mathrm{C}$ temperature rise in two different fire situations.

\begin{tabular}{c|c|c|c}
\hline \multirow{2}{*}{ Detector } & \multicolumn{3}{|c}{ Time to Respond } \\
\cline { 2 - 4 } & Test 1 (elec.) & Test 2 (elec.) & Test 3 (gas) \\
\hline Acoustic Emission & & & \\
\hline Detector & & & $21 \mathrm{~min}$ \\
AE1 & $>5.8 \mathrm{~min}$ & $6 \mathrm{~min}$ & $9 \mathrm{~min}$ \\
AE2 & $>5.8 \mathrm{~min}$ & $>39.5 \mathrm{~min}$ & $7 \mathrm{~min}$ \\
AE3 & $1.3 \mathrm{~min}$ & $1.5 \mathrm{~min}$ & \\
\hline Thermocouple & & & $33.8 \mathrm{~min}$ \\
$\mathrm{~T}_{\text {ae1 }}$ & $>5.8 \mathrm{~min}$ & $21.7 \mathrm{~min}$ & $>34.8 \mathrm{~min}$ \\
$\mathrm{~T}_{\mathrm{ac2}}$ & $>5.8 \mathrm{~min}$ & $33.8 \mathrm{~min}$ & $10.8 \mathrm{~min}$ \\
$\mathrm{~T}_{\mathrm{ae3}}$ & $1.5 \mathrm{~min}$ & $>39.5 \mathrm{~min}$ & $0.2 \mathrm{~min}$ \\
$\mathrm{~T}_{\text {smoke det }}$ & $>5.8 \mathrm{~min}$ & $>39.5 \mathrm{~min}$ & $0.1 \mathrm{~min}$ \\
$\mathrm{~T}_{\max }$ & $0.8 \mathrm{~min}$ & $0.6 \mathrm{~min}$ & \\
\hline
\end{tabular}


was lit, one does not know a priori the location of the maximum temperature in the room.

\section{CONCLUSIONS}

The following conclusions can be drawn based upon analysis of the experiments which were performed:

1. The acoustic emission activity measured previously [1] in $0.5 \mathrm{~m}$ simply supported beams of wood and gypsum board exposed to a small open flame also occurs when these same materials are heated in a structure similar to a full-scale room environment.

2. An acoustic emission transducer is capable of detecting in a full-scale room an open natural gas fire greater than $12 \mathrm{~kW}$ and a $550 \mathrm{~W}$ electrical heater in contact with a wooden beam at a distance up to $3 \mathrm{~m}$ from the heat source.

3. Under the conditions similar to those in the current test, an acoustic emission transducer may detect the threat of a fire as quickly as or faster than a thermocouple or smoke detector. (No claim is made that the AE device would respond more quickly than a smoke detector under other realistic fire conditions.)

4. Additional research is required to identify non-fire sources of $\mathrm{AE}$ emission so that a threatening situation can be unambiguously discriminated from a non-threatening situation.

\section{ACKNOWLEDGEMENT}

The authors wish to acknowledge Roger Clough of the Materials Science and Engineering Laboratory, who provided the acoustic emission measuring equipment and guidance for its application. Assistance from R. Zile, L. DeLauter and G. Roadarmel in conducting the experiments and from Isa Vazquez during the data reduction is also gratefully acknowledged.

\section{REFERENCES}

1. Grosshandler, W.L., and Jackson, M., "Acoustic Emission of Structural Materials Exposed to Open Flames," Fire Safety Journal 22, 209-228 (1994).

2. Clough, R.B., "The Energetics of Acoustic Emission Source Characterization," Materials Evaluation 45, 556-563, 1987.

3. Wadley, H.N.G., "Acoustic Emission: Nature's Ultrasound," in Review of Progress in Quantitative Nondestructive Evaluation, Vol. 5A, D.O. Thompson and D.E. Chimenti, Eds., 271-293, Plenum Publishing Corp., 1986. 